\title{
Pelatihan Komunikasi Efektif untuk Meningkatkan Efikasi diri Perawat dalam Pelaksanaan Identifikasi Pasien
}

\author{
Roymond H. Simamora \\ Fakultas Keperawatan Universitas Sumatera Utara
}

\begin{abstract}
Abstrak
Latar Belakang: Tujuan Penelitian adalah untuk mengetahui apakah terdapat perbedaan efikasi diri perawat dalam pelaksanaan identifikasi pasien sebelum dan sesudah pelaksanaan pelatihan komunikasi efektif. Metode: Dengan Metode quasi-eksperimen desain one group pretest-posttest. Subjek penelitian adalah 17 orang perawat laki-laki dan 28 orang perawat perempuan di rumah Sakit Kota Medan. Sebelum dan Sesudah perlakuan data dikumpulkan dengan menggunakan kuesioner yang terdiri dari 12 pernyataan untuk komunikasi efektif, 35 pernyataan untuk efikasi diri perawat. Pelatihan dilaksanakan selama 2 hari dengan menggunakan panduan komunikasi efektif dalam pelaksanaan identifikasi pasien.

Hasil: Dari hasil output Paired samples test, nilai mean paired difrence adalah sebesar -13.077. (54.62-67,69= -13.077, dan selisih perbedaan tersebut antara -20,326 sampai dengan -5,828 (95\%). Berdasarkan nilai t hitung 3.930>t tabel 2.179 ini memiliki arti bahwa ada pengaruh pelatihan -2,990 dengan nilai signifikansi 0,002, hal ini menunjukkan bahwa setelah pelaksanaan pelatihan komunikasi efektif, ada peningkatan efikasi diri perawat. Nilai output paired samples test adalah 0.002<0.05 menyatakan bahwa ada pengaruh pelatihan komunikasi efektif terhadap peningkatan efikasi diri, hal ini juga didukung dengan nilai koefisien korelasi sebesar 0.350 dengan nilai signifikansi sebesar 0.002,ini menunjukkan tingkat hubungan yang kuat, yang berarti pemberian pelatihan komunikasi efektif memberikan efek yang besar untuk meningkatkan efikasi diri perawat dalam pelaksanaan identifikasi pasien.

Kesimpulan: Menjamin kualitas asuhan dibutuhkan sumber daya manusia (SDM) yang berkualitas juga, untuk mengawal kualitas SDM dapat dilakukan melalui: pendidikan berkelanjutan, sertifikasi, pengakuan kompetensi, supervisi, choaching, dan kegiatan pendukung lainnya.

Kata Kunci: efikasi diri, identifikasi pasien, komunikasi efektif, pelatihan, perawat
\end{abstract}

\section{Effective Communication Training to Improve Nurses Self Efficacy in the Implementation of Patient Identification}

\begin{abstract}
Background: The purpose of this study was to determine whether there were differences in nurse's self-efficacy in the implementation of patient identification before and after the implementation of effective communication training.

Method: With the quasi-experimental method of one group pretest-posttest design. The subjects of the study were 17 male nurses and 28 female nurses at Medan City Hospital. Before and After treatment the data was collected using a questionnaire consisting of 12 statements for effective communication, 35 statements for the nurse's self-efficacy. The training was carried out for 2 days using effective communication guidelines in the implementation of patient identification.

Result: From the results of the Paired samples test output, the mean paired difrence value is -13,077. (54.62$67.69=-13.077$, and the difference between $-20,326$ to $-5,828(95 \%)$. Based on the value of t arithmetic 3,930> t table 2,179 this means that there is an influence of training -2.990 with a significance value of 0.002, p. this shows that after the implementation of effective communication training, there was an increase in the nurse's self-efficacy, the output value of paired samples test was $0.002<0.05$, indicating that there was an effect of effective communication training on improving self-efficacy, this was also supported by a correlation coefficient of 0.350 with a significance value of 0.002, this shows the level of strong relationships, which means the provision of effective communication training has a great effect to improve the self-efficacy of nurses in the implementation of patient identification.

Conclusion: Guarantine the quality of care required quality human resources $(H R)$ as well, to oversee the quality of HR can be done through: continuing education, certification, competency recognition, supervision, choaching, and other supporting activities.

Keywords: self-efficacy, patient identification, effective communication, training, nurses

\begin{tabular}{l}
\hline Alamat Korespondensi: \\
Roymond H. Simamora \\
Fakultas Keperawatan Universitas Sumatera Utara \\
Jalan Prof. T. Ma As No.3 Medan \\
Email: roymond_oy@yahoo.com
\end{tabular}
\end{abstract}

Jurnal Ilmiah Kesehatan Masyarakat Vol. 12 Edisi 1, 2020 


\section{PENDAHULUAN}

Rumah sakit sebagai fasilitas pelayanan kesehatan merupakan bagian dari sumber daya yang diperlukan dalam mendukung upaya penyelenggara kesehatan. Pelayanan rumah sakit yang bermutu sesuai standar pelayanan merupakan harapan semua pengguna ${ }^{1}$. Pemerintah telah melakukan upaya untuk pencapaian tersebut, diantaranya melalui akreditasi. Dalam standar akreditasi rumah sakit tahun 2017 terdiri dari standar: pelayanan berfokus pasien, manajemen rumah sakit, sasaran keselamatan pasien dan standar program MDGs ${ }^{1}$. Keselamatan pasien indentik dengan kualitas pelayanan, semakin baik kualitas layanan maka keselamatan pasien juga akan semakin baik. Tujuan pengembangan program Keselamatan pasien (patient safety) di rumah sakit adalah, menciptakan budaya patient safety, memperbaiki akuntabilitas rumah sakit, melakukan pencegahan kejadian yang tidak diinginkan tidak terulang kembali $^{2}$. Salah satu komponen tenaga pelayan kesehatan di rumah sakit adalah perawat. Perawat berinteraksi langsung terhadap pasien dengan intensitas yang paling tinggi dibandingkan dengan komponen yang lainnya. Perawat bekerja dalam shift karena rumah sakit melayani pasien selama 24 jam. Keadaan seperti ini apabila berlangsung terus-menerus akan menyebabkan perawat mengalami kelelahan fisik, emosi, dan mental sering disebut burnout yang dapat mempengaruhi kepercayaan diri dalam pelayanan termasuk dalam pelaksanaan identifikasi pasien ${ }^{3}$. Keamanan pasien di rumah sakit dimulai dari ketepatan identifikasi. Kesalahan identifikasi diawal akan berdampak pada kesalahan pelayanan tahap berikutnya. Rumah sakit harus menjamin seluruh profesi yang terlibat dalam proses identifikasi, kegiatan ini harus berjalan dengan benar sejak pertama kali pasien didaftarkan. Proses identifikasi dimulai dari pasien masuk rumah sakit dan akan terus dikonfirmasi pada pelayanan tindakan berikutnya, sampai pasien dinyatakan pulang. Kesalahan dalam mengidentifikasi pasien dapat terjadi dihampir semua tahapan diagnosis dan pengobatan ${ }^{3}$. Hal ini dapat terjadi karena keterbatasan ruang dan waktu dalam membangun proses interaksi antara pasien dengan perawat, perawat dengan tim kesehatan lainnya. Sasaran keselamatan pasien yang pertama menyebutkan bahwa identifikasi pasien penting untuk mengidentifikasi pasien yang akan mendapatkan pelayanan agar tidak terjadi kekeliruan ${ }^{4}$. Data laporan keselamatan pasien pemerintah Australia bagian selatan terdapat 5 jenis kesalahan identifikasi pasien yang sering terjadi pada tahun 2014-2015 yaitu salah mengidentifikasi pasien 273 kasus, kesalahan label pada spesimen 272 kasus, salah pasien 211 kasus, salah status rekam medis 59 kasus dan kesalahan hasil pemeriksaan sebanyak 28 kasus $^{5}$.

Dalam pelaksanaan identifikasi pasien, perawat sering sekali menemui hambatan, hambatan ini berupa keterbatasan komunikasi, yang diakibatkan dengan pekerjaan yang akan segera diselesaikan, efek yang timbul adalah burnout. Burnout adalah menurunnya motivasi terhadap kerja, sinisme, timbulnya sikap negatif, frustasi, timbul perasaan ditolak oleh lingkungan, dan gagal, yang mempengaruhi efikasi diri perawat ${ }^{6}$. Perawat dituntut untuk memiliki disposisi perilaku tertentu agar dapat menyelesaikannya. Salah satu disposisi perilaku tersebut ialah efikasi diri (Self efficacy). Efikasi diri diartikan sebagai suatu keyakinan tentang kemampuan untuk dapat menyelesaikan pekerjaan dengan berhasil ${ }^{7}$. Efikasi diri mengacu pada keyakinan individu mengenai kemampuannya memobilisasi motivasi, sumber daya kognitif dan tindakan yang diperlukan agar berhasil melaksanakan tugas dalam konteks tertentu. Efikasi diri yang tinggi akan mengembangkan kepribadian yang kuat pada seseorang, mengurangi stres dan tidak mudah terpengaruh oleh situasi yang mengancam. Berbeda dengan individu dengan self efficacy rendah, individu tersebut akan cenderung tidak mau berusaha atau tidak menyukai pekerjaan sama dalam situasi yang sulit dan tingkat kompleksitas yang tinggi ${ }^{7}$. Perawat bertemu dengan banyak pasien beserta keluarga, memerlukan kemampuan komunikasi, serta rasa percaya diri untuk memberikan layanan asuhan kesehatan, apabila perawat memiliki Self efficacy yang buruk maka hal ini dapat merugikan pasien dan dapat mengakibatkan kesalahan kerja yang mengancam nyawa pasien $^{8}$. Dunia layanan kesehatan membutuhkan orang-orang dengan kemampuan komunikasi yang baik, karena melalui komunikasi, apa yang dibutuhkan oleh pasien, dan apa yang akan diberikan dapat tersampaikan dengan aman dan nyaman. Komunikasi sebenarnya dapat dikembangkan dan dilatih, ketika individu terbiasa untuk melakukan komunikasi yang efektif maka kebiasaan itu akan terus terbawa9 . Ketika seseorang mempunyai ketrampilan komunikasi yang baik, maka hal itu akan menjadikan seseorang percaya diri dan 
memungkinkan seseorang untuk mengerahkan lebih atas kontrol hidup mereka ${ }^{10}$. Beberapa ketrampilan berkomunikasi lebih penting untuk keberhasilan pekerjaan dibandingkan dengan ketrampilan tehnis tertentu. Tidak ada keahlian yang lebih penting untuk karir yang sukses dalam pelayanan jasa daripada komunikasi yang baik $^{10}$. Tidak semua orang memiliki kemampuan untuk dapat berkomunikasi secara efektif, masih terdapat orang-orang yang kurang memiliki ketrampilan komunikasi yang baik. Berdasarkan latar belakang tersebut peneliti tertarik melakukan penelitian: Pelatihan Komunikasi Efektif untuk Meningkatkan Efikasi diri Perawat dalam Pelaksanaan Identifikasi Pasien.

\section{METODE}

Merupakan penelitian kuantitatif dengan rancang penelitian quasi-experiment dengan One Group Pretest-Posttest Design. Subjek dalam penelitian ini adalah 45 orang perawat pelaksana dari salah satu rumah sakit dikota Medan, yang telah diberikan informed consent. Data dikumpulkan menggunakan kuesioner, 12 pernyataan untuk komunikasi efektif, 35 pernyataan untuk efikasi diri perawat dalam pelaksanaan identifikasi pasien, yang telah di uji reabilitas dan validitas penggunaanya. Prosedur Penelitian: langkah awal setelah informed consent peneliti menyebarkan kuisioner kepada Perawat yang telah mengahiri shift-nya, hasil olahan data disajikan dalam Forum Group discussion, disepakati untuk melakukan pelatihan. Pelatihan dilakukan selama 12 jam pembelajaran selama 2 hari, dengan materi: konsep dasar komunikasi efektif, konsep efikasi diri, komunikasi efektif dalam pelaksanaan identifikasi pasien, disampaikan melalui ceramah, diskusi kelompok dan role play. Dua minggu setelah pelatihan, dilakukan pengumpulan data kembali, dan melakukan observasi terhadap perawat dalam pelaksanaan Identifikasi pasien, yang dilakukan selama 2 minggu. Data diuji normalitas, kemudian data dianalisis menggunakan paired samples t-test untuk mengetahui perbedaan sebelum dan sesudah pelatihan, dan menggunakan uji Spearman Rank, untuk mengetahui hubungan pelatihan komunikasi efektif dengan peningkatan efikasi diri perawat dalam pelaksanaan Identifikasi pasien.

\section{HASIL}

Karakteristik responden pada penelitian ini adalah: 17 orang perawat laki-laki, dan 28 orang perawat perempuan. dimana $43,1 \%$ berusia 25 tahun atau lebih, $62,4 \%$ suku batak. Kemampuan komunikasi efektif perawat sebesar $66.55 \%$ termasuk dalam kategori kurang baik. Hasil pre test skill komunikasi efektif pada perawat sebelum diberikan pelatihan menunjukan sebesar $66.55 \%$ termasuk dalam kategori kurang baik. Setelah diberikan perlakuan berupa pemberian materi dan simulasi komunikasi efektif pada saat pelaksanaan identifikasi pasien terdapat peningkatan skill komunikasi dimana $(96,6 \%)$ orang dalam kategori baik. Terjadi peningkatan kemampuan komunikasi efektif setelah diberikan pembelajaran role-play komunikasi efektif dan melaksanakan identifikasi pasien. Untuk tingkat self-efficacy, menunjukkan gambaran yaitu, sebanyak 25 orang $(54,8 \%)$ memiliki tingkat self efficacy rendah dan sebanyak 22 orang $(45,2 \%)$ memiliki tingkat self efficacy yang sedang. Sebelum pelatihan diperoleh, nilai rata rata efikasi diri Perawat tentang pelaksanaan Identifikasi Pasien sebesar 54.62, dan setelah pelatihan adalah 67.69 , karena $54,62<67.69$ secara deskriptif ada perbedaan rata-rata efikasi diri perawat setelah pelatihan.

Dari hasil output Paired samples test, nilai mean paired difrence adalah sebesar 13.077. (54.62-67,69 = -13.077), dan selisih perbedaan tersebut antara $-20,326$ sampai dengan $-5,828$ (95\%). Berdasarkan nilai t hitung 3.930 $>t$ tabel 2.179 ini memiliki arti bahwa ada pengaruh pelatihan $-2,990$ dengan nilai signifikansi 0,002 , hal ini menunjukkan bahwa setelah pelaksanaan pelatihan komunikasi efektif, ada peningkatan efikasi diri perawat dalam pelaksanaan identifikasi pasien, Berdasarkan output paired samples test diketahui nilai sig.(2-tailed) adalah $0.002<0.05$ menyatakan bahwa ada pengaruh pelatihan komunikasi efektif terhadap peningkatan efikasi diri Perawat dalam pelaksanaan identifikasi pasien, hal ini juga didukung dengan uji paired samples $t$ test nilai koefisien korelasi sebesar 0.350 dengan nilai signifikansi sebesar 0.002 . karena nilai sig $<0.05$, hasil ini menunjukkan ada hubungan yang signifikan antara pelatihan komunikasi efektif dengan peningkatan selfefficacy dalam pelaksanaan identifikasi pasien. Kekuatan hubungan pada penelitian ini menunjukkan tingkat hubungan yang kuat, yang 
berarti pemberian pelatihan komunikasi efektif memberikan efek yang besar untuk meningkatkan efikasi diri perawat dalam pelaksanaan identifikasi pasien.

\section{PEMBAHASAN}

Komunikasi merupakan hal yang sangat penting dalam menciptakan kerjasama antar tim guna tercapainya pelayanan kesehatan yang optimal. Selain itu komunikasi juga dapat membangun suasana dan hubungan kerja yang positif. Ketrampilan dalam berkomunikasi selama pelaksanan identifikasi pasien merupakan bagian yang sangat penting untuk mencapai hasil perawatan yang diberikan kepada pasien secara optimal, serta menurunkan medical error diakibatkan kegagalan komunikasi oleh petugas kesehatan, didalamnya termasuk perawat $^{11}$. Diperlukan strategi pembelajaran tentang komunikasi efektif secara sistematis untuk meningkatkan keamanan dan perawatan berkualitas. Berdasarkan hasil penelitian didapatkan karakteristik responden berusia 25 tahun atau lebih. Usia 25-an merupakan masa puncak perkembangan intelektual sehingga proses pembelajaran akan mudah diterima dan lebih peka terhadap stimulasi yang diberikan ${ }^{12}$. Usia merupakan hal yang penting karena mempengaruhi kematangan kognitif, perkembangan intelektual, kepribadian, dan emosional $^{13}$. Hal ini sesuai dengan hasil penelitian dimana seluruh responen menunjukkan adanya perubahan kemampuan skill komunikasi efektif dari kurang baik dan berubah menjadi baik setelah diberikan stimulasi berupa pembelajaran komunikasi efektif ${ }^{14}$. Hasil penelitian tentang perubahan skill komunikasi menunjukkan adanya peningkatan. Terdapat peningkatan kemampuan komunikasi dalam kategori baik, hal ini sesuai dengan pendapat yang disampaikan ahli bahwa perilaku dapat dibentuk dari pengaruh orang lain dan lembaga pendidikan ${ }^{15}$. Orang disekitar kita merupakan salah satu komponen sosial yang ikut mempengaruhi sikap dan perilaku seseorang. Orang tersebut merupakan seseorang yang dianggap penting, diharapkan memberikan persetujuan pada setiap perbuatan, seperti orang tua, guru, orang yang memiliki status sosial lebih tinggi. Selain itu proses pendidikan juga memberi peran dalam pembentukan sikap yang dapat merubah perilaku seseorang, karena proses pendidikan mengajarkan konsep dasar, termasuk konsep tentang komunikasi efektif ${ }^{16}$. Hal ini sesuai dengan hasil penelitian ini dimana sebagian besar responden mengalami perubahan perilaku yang nampak pada kemampuan skill komunikasi. Perubahan tersebut terjadi setelah diberikan serangkaian proses pembelajaran berupa role play. Skill komunikasi efektif mengalami peningkatan setelah mendapatkan pembelajaran termasuk dalam kategori baik setelah mendapatkan perlakuan. Setelah dilakukan simulasi menggunakan kasus nyata, seluruh responden mengalami peningkatan skill komunikasi termasuk dalam kategori baik. Untuk tingkat self efficacy, menunjukkan gambaran yaitu, sebanyak 25 orang $(54,8 \%)$ memiliki tingkat self efficacy rendah dan sebanyak 22 orang $(45,2 \%)$ memiliki tingkat self efficacy yang sedang. Hal ini menunjukkan responden memiliki keyakinan terhadap kemampuan dirinya untuk melakukan suatu tugas sesuai jobdesk yang ada. Beberapa faktor yang berperan dalam perkembangan self efficacy, diantaranya adalah usia. Menurut Eden, terdapat hubungan antara usia dengan self efficacy dimana dikatakan bahwa semakin bertambah usia seseorang, cenderung memiliki self efficacy yang tinggi? Bertambahnya usia terkait dengan jumlah pengalaman yang semakin banyak, yang juga mempengaruhi cara pikir dan kedewasaan seseorang. Tampaknya hal ini yang mendukung perkembangan self efficacy menjadi semakin tinggi ${ }^{18}$. Demikian juga faktor status pernikahan, dikatakan bahwa seseorang yang telah menikah memiliki self efficacy yang tinggi dibandingkan yang belum menikah, tampaknya hal ini juga terkait dengan faktor usia, pengalaman, dan kematangan yang mempengaruhi cara berpikir individu. Faktor lainnya adalah faktor pendidikan, latar belakang pendidikan yang tinggi juga mampu mendorong seseorang untuk memiliki tingkat self efficacy yang tinggi dikarenakan pengetahuan, kemampuan dan pengalaman yang dimiliki ${ }^{19}$.

Berdasarkan hasil uji statistik menggunakan paired t-test yang dilakukan terhadap skor efikasi diri perawat, dapat dilihat bahwa nilai $\mathrm{p}$ sebesar 0.002 dan hipotesis dapat dikaitkan signifikan apabila $\mathrm{p}$ lebih kecil dari 0,05 , oleh karena itu dapat dikatakan bahwa ada pengaruh pemberian pelatihan komunikasi efektif terhadap efikasi diri perawat. Komunikasi dan efikasi diri sebenarnya dapat dikembangkan dan diasah melalui pengalaman, membaca, observasi dan praktek ataupun dengan pelatihan-pelatihan yang rutin. Selain itu juga dijelaskan bahwa pengembangan komunikasi dapat dilakukan dengan bermacam cara, seperti: learning by doing, berinteraksi dan melakukan aktivitas dengan orang lain. mengikuti pelatihan atau seminar-seminar manajemen ${ }^{20}$. Komunikasi 
dan efikasi diri sebenarnya dapat dikembangkan dan diasah melalui pengalaman, membaca, observasi dan praktek maupun dengan pelatihanpelatihan yang rutin ${ }^{17}$. Pelatihan ketrampilan komunikasi dapat meningkatkan atau mengembangkan kepercayaan diri seseorang dalam aspek komunikasinya. Pelatihan komunikasi adalah suatu bentuk program pelatihan yang dilakukan dengan tujuan untuk memahami prinsip dasar manusia dalam berkomunikasi dan meningkatkan ketrampilan komunikasi $^{21}$. Pemberian pelatihan juga merupakan salah satu sumber untuk mengembangkan efikasi diri seseorang, yaitu mastery experiences. Mastery experiences merupakan cara paling efektif untuk menciptakan rasa yang kuat akan keberhasilan seseorang melalui penguasaan pengalaman. Penguasaan pengalaman yang dimaksud dalam penelitian ini adalah dengan memberikan penguasaan berupa pelatihan komunikasi efektif ${ }^{18}$.

\section{KESIMPULAN}

Ada perbedaan kemampuan Komunikasi dan efikasi diri perawat setelah dilakukan pelatihan, diperoleh nilai-2,990 dengan nilai signifikansi 0,002, hal ini menunjukkan bahwa setelah pelaksanaan pelatihan komunikasi efektif, ada peningkatan efikasi diri perawat dalam pelaksanaan identifikasi pasien, hal ini juga didukung dengan nilai efect size sebesar 1,37 yang berarti pemberian pelatihan komunikasi efektif memberikan efek yang besar untuk meningkatkan efikasi diri perawat dalam pelaksanaan identifikasi pasien. Berdasarkan hasil uji hubungan antara pelatihan komunikasi efektif dengan self efficacy perawat dalam pelaksanaan identifikasi pasien melalui analisis data dengan uji Spearman Rank diperoleh nilai $r=0,660$ dengan $p=0,000 \quad(p<0,05)$. Hasil ini menunjukkan ada hubungan yang signifikan antara pelatihan komunikasi efektif dengan peningkatan self efficacy dalam pelaksanaan identifikasi pasien. Kekuatan hubungan pada penelitian ini menunjukkan tingkat hubungan yang kuat. Saran: Peningkatan kemapuan staf keperawatan diharapkan mampu merangsang minat dalam pengembangan pribadi perawat dengan tujuan meningkatkan hasil karya dan prestasi dengan cara memberikan umpan baik kepada mereka tentang prestasinya serta menyusun program pengembangan dan pelatihan staf. Sehingga Rumah sakit memiliki tenaga yang cakap dan terampil untuk pengembangan pelayanan keperawatan.

\section{ACKNOWLEDGEMENT}

Kegiatan ini didanai oleh DRPM Kemenristekdikti RI tahun Anggaran 2019

\section{DAFTAR PUSTAKA}

1. KARS. SNARS Edisi I, Jakarta. 2017

2. Joint Comission Resource. Patient Safety: Essential For Health Care. 2012

3. Thisna Sari Umaternate., Lucky. T., Kumaat Mulyadi. Hubungan Pelaksanaan Identifikasi Pasien secara benar dengan Kepuasan pasien di IGD RSU. Prof. Dr. R.D. Kandou Manado. E-Journal Keperawatan (e-Kp), 2013; 3.2

4. Anggraeni Dewi,, Lukman Hakim., dan Cecilia W. Imam. 2014. Evaluasi Pelaksanaan Sistem Identifikasi Pasien di Instalasi Rawat Inap Rumah Sakit. Jurnal Kedokteran Brawijaya. 2014; 8.1

5. Coulter A, Ellins J. Analysis: Effectiveness of strategies for informing educating and involving patients. BMJ. 2007; 24-7.

6. McDonald A. A Long and Winding Road: Improving communication with patients in the NHS. 2016

7. Eden, D \& Aviram, A. Self-efficacy training to speed reemployment: helping people to help themselves. Journal of Application Psychology, 2013; 8 (3), 352360.

8. Mulyani, Mustika Dwi. Hubungan antara Manajemen Waktu dengan Self regulated. Educational Psychologi Journal. 2013; 2 (1).PP 43-48

9. Jones J. Foreword. In: Kraszewski S, McEwen A (eds) Communication Skills for Adult Nurses. Maidenhead: Open University Press. 2010

10. Bernadin, John. Human Resources Management an Experiental approach. Singapura: Mc Graw Hill, inc. 2012

11. Fitria, Cemy Nur. Efektifitas Pelatihan Komunikasi SBAR dalam Meningkatkan Motivasi dan Psikomotor Perawat di Ruang Medikal Bedah RS PKU Muhammadiyah Surakarta, Prosisding Konfrensi Nasional PPNI Jawa Tengah. 2013

12. Joffe Erel., Turley James P., Hwang Kevin O., Johnson Todd R., Johnson Crag 
W., Berstem Elmer V. Evaluation of a Problem-Specific SBAR Tool to Improve After-Hours Nurse-Physician Communication. The Joint Commission Journal on Quality and Patient Safety. 2013;11 PP. 495-507. (Diakses tanggal 31 Mei

http://psnet.ahrg.gov/resource.aspx/ resourceID=26967

13. Chan,Zenobia C.Y. Role-playing in the problem-based learning class, NEP. 2012. (Diakses tanggal 9 Mei 2019). http://www.ncbi.nlm.nih.gov/pubmed/216 $\underline{01528}$

14. Dora, M. T. dan Kadir, H. A. Mengurus Stres. Jakarta. Proffesional Publishing. 2014

15. Prasetyo, B. \& Haryanto. Pengaruh model pembelajaran problem based learning (PBL) terhadap kemampuan pemecahan masalah. Dalam Leonard (Editor). Jakarta: UNINDRA Press. EduResearch. 2015: Vol. 1

16. Mahmudi, M. H \& Suroso. Efikasi diri, Dukungan Sosial, Dan Penyesuaian Diri Dalam Belajar. Jurnal Psikologi
Indonesia, 2014; Vol. 3, No. 02, hal 183194

17. Simamora R.H. Komunikasi Dalam Keperawatan. Jember University Press. 2010

18. Riaz, Z., Yasien, S., \& Khanam, S., J. Translation and adaptation of perceived social self efficacy scale (PSSE). Pakistan Journal of Psychology. 2011;42 (2), 7992.

19. Iroegbu, M, N. Self efficacy and work Performance: A theoretical framework of Albert Bandura's model, review of findings, implications and directions for future research. Journal Psychology and Behavioral Sciences. 20154 (4) : 170173.

20. Femi, A.F. The Impact of Communication on Workers ${ }^{\text {ec }}$ Performance in Selected Organisations in Lagos State, Nigeria". IOSR-JHSS, 2012;19. 8 PP 75-82.

21. Kibe, C.W. Effects of Communication Strategies on Organizational Performance: A Case Study of Kenya Ports Authority". European Journal of Bussiness and Management. 2014; Vol. 6.11 